\title{
PHONEMIC CHARTS ALONE ARE NOT ENOUGH
}

\author{
YAO SHEN \\ University of Michigan
}

In the analysis of any language according to the descriptive linguistic procedure, one must study the phonology, morphology, and syntax of the language. In each of these three subjects, devices functioning within its own structure can be discovered, and the devices and structures vary from language to language. In the analysis of syntactical structure, the linguist observes the syntactical patterns, such as the use of function words, word order, and inflection ${ }^{\prime}$ in various patterns found in English. ${ }^{2}$ In the analysis of the morphological structure, for example that in English, he contrasts the morphological devices within the morphological patterns, such as the four form classes in contrast with each other. ${ }^{3}$ Even though the demarkation between morphology and syntax is not yet clearly drawn, in his description of the language, he records the different kinds of function words that can be used with each form class. ${ }^{4}$ In the analysis of the phonological structure, he identifies the sounds and their patterns. The study of the sound patterns involves the separating of individual meaning distinguishing sound-features or phonemes, the grouping of non-meaning distinguishing soundfeatures or phonetic differences into phonemes, the recognizing of the distribution of sounds and their features, and the possibility of sound combinations. 5 The result of this study on the phonological structure thus obtained is usually presented in a phonemic chart made up of phonemes arranged according to their points of articulation. This phonemic chart, however, does not show the submembers of the phonemes, the variations of a phoneme due to certain distribution, and the possible phoneme combinations or the arrangement of phonemes or the

\footnotetext{
${ }^{1}$ See Charles C. Fries, American English Grammar, D. Appleton-Century Co., New York, 1940, Chapters V-X.

${ }^{2}$ See Charles C. Fries, The Structure of English, Harcourt, Brace, and Co., New York, 1952, Chapter VIII.

'Ibid., Chapter VII.

${ }^{4}$ Ibid., Chapter VI.

${ }^{5}$ Edward Sapir, “Sound Patterns in Language," Language, I(1925), 37-51.
} 


\title{
PHONEMIC CHARTS ALONE ARE NOT ENOUGH
}

\author{
Chinese (Nanking dialect): \\ $[1-] \sim[\mathrm{n}-]$ nasal variant of [1-] \\ light night (pronounced interchangeably)
}

f) English:

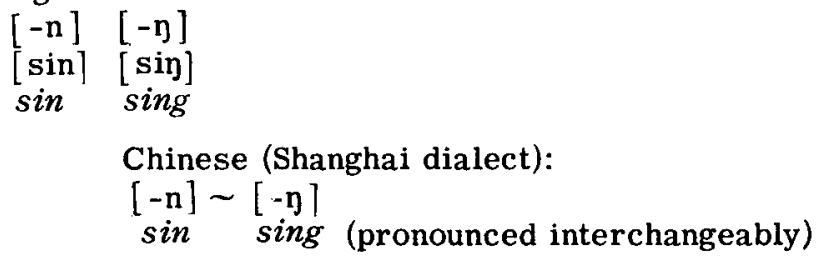

3) Submembers of a phoneme in the student's foreign language which are not found in the student's native language must be mastered separately. Most theoretical linguists state that there are three vowel sounds in Mandarin Chinese. They are high, mid, and low. There are five submembers in the high vowel. They are $[\dot{i}]{ }^{9},[\ddot{u}],[z],[r]$, and $[u] .10$ Of these five, the middle three are not found in English. For the English speakers, the production of each of these three requires the establishing of new habits. And the problems involved in the production of the three sounds are not the same. English speakers learning Mandarin Chinese will find that if the teacher gives detailed description for the production of [z] and [ $r$ ] and sufficient drills are used, their new habits are not particularly difficult to establish. However, the problem of the production of $[\ddot{u}]$ is somewhat different. There are in English the [i] sound which has the tongue position of [ï] and the [u] sound which has the lip position of $[u]$. Although students do not often produce [ $\ddot{i}]$ as $[i]$, they usually confuse [ $\ddot{\mathbf{u}}]$ with [u]. Thus for

"uǒ [ ¿ ‘ùu] Detroit" (I go to Detroit), students sometimes say:

"uð [とì] Detroit" (I make Detroit mad),

or very often say:

"uǒ * [cu] Detroit" (I chew Detroit).

${ }^{9}$ The Chinese [i] sound may be pronounced as [i] in [ist] east or in [il] eelor as [ $\mathrm{I}]$ in [ $\mathrm{I} 1]$ ill or as [y] in [yist] yeast.

${ }^{10}$ The Chinese [u] sound is phonetically different from the English [u] as in [ful] fool. The lips are more closed and less rounded than the English [u]. "The tongue is retracted rather than raised." See Y. R. Chao, Mandarin Primer, Harvard University Press, 1948, p. 23. 


\section{YAO SHEN}

environment of arrangements. In other words, the phonemic chart often does not show the phonological structure of the language.

A few examples are given below. In English, the vowel sound [a] as in father combines with $[\mathrm{I}]$ and [ $\mathrm{U}]$ to form [ar] and [au] as [bar] buy and [bau] bow. The vowel sound [0] as in ball combines with [ $\mathrm{I}$ ] to form [0r] as in [borl] boil. These two vowel sounds do not combine with other vowel sounds. The consonant sounds [s-] as in [sar] sigh, [p-] as in [par] pie, and $[\mathrm{r}-]$ as in [rar] rye may combine to form [ $[\mathrm{sp}-]$ as in [spar] spy and [pr-] as in [prar] pry and further combine to form [spr-] as in [sprar] spry. In that specific position, one does not find other combinations. The same $[s],[p]$ and [r] may be found in final positions, such as $[-s]$ in [hIs ] hiss, [-p] in [hr p] hip, and [-r] in [hrr] here. These three sounds in final position may also be found in combinations. The distribution of the combinations finally, however, is different from that initially. From the following two lists, one can see that the only combination of these three sounds that occurs in both positions is [sp].

Initially:

$\begin{array}{ll}\text { [sp] } & \text { spy } \\ {[\mathrm{pr}]} & \text { pry } \\ {[\mathrm{spr}]} & \text { spry }\end{array}$

Finally:

$\begin{array}{ll}\text { [sp] } & \text { wasp } \\ \text { [sps] } & \text { wasps } \\ {[\mathrm{rp}]} & \text { burp } \\ \text { [rps] } & \text { burps } \\ \text { [ps] } & \text { maps } \\ {[\mathrm{rs}]} & \text { purse }\end{array}$

In Mandarin Chinese, there is the [s-] as in sān 'three', $[\mathrm{t}-]$ as in tán 'to talk', and [ $\mathrm{r}-]^{6}$ as in rán 'to burn', literary form. There is the final $[-\mathrm{r}]^{7}$ as in rér 'a small child'. But there is no $[s]$ and $[p]$ finally. Furthermore, there are no consonant clusters as those found in English in either position.

A knowledge of the phonological structures of languages is essential in the teaching of foreign languages. In the mastery

\footnotetext{
${ }^{6}$ The Chinese [ $r-$ ] differs from the English [ $\left.r-\right]$ in two respects. 1) It has no lip action unless when followed by a rounded vowel. 2) It is shorter and has more friction. See Y. R. Chao, Mandarin Primer, Harvard University Press, 1948, p. 21. When stressed, [r-] is like a fricative.

${ }^{7}$ The Chinese $[-r]$ is very much like an American $[-r]$.
} 


\section{PHONEMIC CHARTS ALONE ARE NOT ENOUGH}

of the sounds in a for eign language, the difficulties involved are more numerous in number and complicated in nature than the phonemic charts can show. It is true that whatever difference found in the comparison of any two phonemic charts is an important point that needs special attention. This does not imply that whatever is not shown in the phonemic charts is non-important or that it is all-important. Because of the differences existing between the two phonological structures of any two languages, the nature of the problems involved vary from language to language. A comparison of the phonemic charts of any two languages can predict some teaching problems, for example, phonemes in the foreign language which are not found in the student's native language and which require the establishing of new habits. But the problems involved in the production of a stream of sounds are more than just the mastery of individual phonemes. Various kinds of examples are given below to show the importance of a knowledge of the phonological structures of the languages concerned.

1) Phonemes that are found in the foreign language and which are not found in the student's native language are usually confused with some phoneme or submember of a phoneme in the student's native language.
a) English: [0-]
[
Chinese: [ aagk] is often pro-
Japanese: nounced as
Spanish:
tank
Portugese: sank
Persian:
* fank
b) English: $\begin{aligned} & {[\mathrm{r}-] } \\ & {\left[\begin{array}{r}\text { rais }] \\ \text { rice }\end{array}\right.}\end{aligned}$
Japanese: [rars] is often pro- Chinese: nounced as (Cantonese) lice

2) Submembers of a phoneme in the student's native language which are separate phonemes in the foreign language are always points that need special attention. Due to the distribution of submembers, some sounds may have one-way confusions. 


\section{YAO SHEN}

a) English:

$$
\begin{aligned}
& {[\mathrm{h}-]} \\
& {[\mathrm{f}-]} \\
& \text { hive }] \\
& \text { [farv] }
\end{aligned}
$$

Japanese:

$[\mathrm{h}-]$ before $[\mathrm{a}] \sim[\mathrm{f}-]$ bilabial

$$
\text { hive five (pronounced as hive) }
$$

b) English:

$$
\begin{array}{ll}
{[\zeta-]} & {[\mathrm{s}-]} \\
{[\text { 'šıggl] }} & {[\text { 'singal }]} \\
\text { shingle } & \text { single }
\end{array}
$$

Japanese:

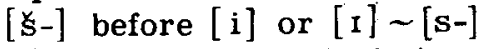

shingle single (pronounced as shingle)

c) English:

$$
\begin{array}{cc}
{[\mathrm{w}-]} & {[\mathrm{v}-1} \\
{[\text { waIn] }} & {[\text { vain] }} \\
\text { wine } & \text { vine }
\end{array}
$$

Chinese (Mandarin):

$$
\begin{aligned}
& \left.[\mathrm{w}-]^{-} \sim \mathrm{v}-\right]^{\mathrm{8}} \\
& \text { wine }
\end{aligned}
$$

d) English:

$$
\begin{aligned}
& \text { [b-] [v-] labio-dental } \\
& \text { [bot] [vot] } \\
& \text { boat vote } \\
& {[\mathrm{b}-] \sim[\mathrm{v}-] \text { bilabial }} \\
& \text { [bot] [vot] } \\
& \text { boat vote (pronounced as boat) }
\end{aligned}
$$

Others may have two-way confusions.

e) English:

$$
\begin{array}{ll}
\text { [1-] } & {[\mathrm{n}-]} \\
\text { [lart] } & \text { [nart] } \\
\text { light } & \text { night }
\end{array}
$$

\footnotetext{
${ }^{8}$ Especially when unstressed.
} 
4) Significant sounds found in the phonemic chart of the foreign language which are not found in the student's native language are without doubt points that need special attention. But significant sounds found in both languages do not always mean no trouble. Often the problem involved is not that the sound is not found in the student's native language, but rather it is because the environment of the same sound or same sounds is different. In other words, the position where the same sound occurs may be different, the distribution of the same sound may be different, the arrangement of the same sound may be different, or the arrangement of the same sound sequence may be different.

In both English and Mandarin Chinese there is the sound $[\cdot \mathrm{ts}]$. However, in Chinese [ts] occurs initially, and in English the sound [ts] occurs finally. It is just as difficult for the English speaker to produce the initial [ $t s$ ] in Chinese as it is for the Chinese speaker to produce the final [ts] in English. The sound is found in both languages, but the position where the sound occurs is different.

$$
\begin{aligned}
& \text { English: } \\
& \text { [-] [-ts] } \\
& \text { Chinese: } \\
& \text { [ts-] [-] }
\end{aligned}
$$

A comparison of the phonemic charts of English and Spanish will show that there is the sound $[\mathrm{m}]$ in both languages. But this does not necessarily mean that some Spanish speakers when learning English will find no difficulty in producing $[\mathrm{m}]$. It is true that they have no trouble in producing $[\mathrm{m}]$ in initial position as in [mek] make. In final position, however, the [m] sound is at times pronounced as [n ]. Thus

Did you see the hem is pronounced as Did you see the hen. Did you see the bum is pronounced as Did you see the bun.

The reason for this confusion is that there is no final $m$ in Spanish. Consequently the final $[m]$ is often pronounced as final $[\mathrm{n}]$.

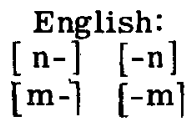

$$
\begin{aligned}
& \text { Spanish: } \\
& {[\mathrm{n}-][-\mathbf{n}]} \\
& {[\mathrm{m}-][-]}
\end{aligned}
$$

In other words, the distribution of the sound $[\mathrm{m}]$ is different. 


\section{YAO SHEN}

Sounds found in both languages may combine differently or are arranged differently. A comparison of the phonemic charts of Mandarin Chinese and English will show that the sound [a ] as in father and the sound [y] as in thing are found in both languages. Only a comparison of the phonological structures will indicate that in Mandarin, $[\eta]$ can be preceded by [a] to form [ay]. In English [ $\mathrm{g}]$ is usually not preceded by [a]. Consequently, English speaking students often produce [an] as [ aen ]. One often hears Miss [wán] addressed as Miss [wán] and Miss [yán] addressed as Miss [yáen]. The reason for this phenomenon is not because the English speaker cannot produce [a] or [ $\mathrm{g}]$. Rather it is because they are not accustomed to this new arrangement.

A close examination of the phonemic charts of Mandarin Chinese and English will show that in both languages there are $[s],[t]$, and $[r]$. For example:

$\begin{array}{ll}\text { Chinese: } & \text { English: } \\ \text { sù (to model a figure in clay) } & \text { sue } \\ \text { tù (to vomit) } & \text { two } \\ \text { rù (to enter, literary form) } & \text { rue }\end{array}$

But a study of the phonological structures of the sounds will reveal something further. That is, in English one will find stew, true, and strew. Such combinations as [st], [ tr] , and [str] are not to be found in Mandarin. Hence the Mandarin speaker will find it difficult to produce such sounds as consonant clusters. In the production of stew, true, and strew, and other consonant clusters, he often inserts a vowel between every two consonant sounds. ${ }^{11}$ For it is within his established habit that an initial consonant sound is usually followed by a vowel sound. Such trouble is certainly due to the difference in the arrangement of sounds.

In the teaching of English to Spanish speakers, quite often emphasis is placed on the aspiration necessary in producing initial $[\mathrm{p}],[\mathrm{t}]$, and $[\mathrm{k}]$ not prèceded by $[\mathrm{s}]$. In Spanish such sounds are not aspirated. However, in English when [p], $[\mathrm{t}]$, and $[\mathrm{k}]$ are preceded by $[\mathrm{s}]$ to form $[\mathrm{sp}-],[\mathrm{st}-]$, and $[\mathrm{sk}-]$, the $[\mathrm{p}],[\mathrm{t}]$, and $[\mathrm{k}]$ are not aspirated. This does

"For example, They prayed down the street and They parade down the street are pronounced alike. 


\section{PHONEMIC CHARTS ALONE ARE NOT ENOUGH}

not mean that Spanish speakers have no trouble in producing $[\mathrm{sp}-],[\mathrm{st}-]$, and $[\mathrm{sk}-]$. It is true that the aspiration is no longer necessary. But in Spanish, initial $[\mathrm{sp}]$, [st], and [sk] are usually preceded by a vowel, especially in utterance initial. Thus the Spanish speaker often does not distinguish

$\begin{array}{rlr}\text { spot } & \text { and } & \text { a spot } \\ \text { street } & \text { and } & \text { a street } \\ \text { school } & \text { and } & a \text { school } \\ \text { I'm going to school } & \text { and } & \text { I'm going to a school }\end{array}$

In other words, the environment of the same sound sequence is different.

The above examples are given to illustrate the fact that a mere comparison of the phonemic charts of the student's native language and the foreign language is not sufficient in the teaching of foreign languages. It is essential to compare the phonological structures of both languages. All that is to be found in the phonemic charts is essential. But what is found concerning the sound system which is outside the phonemic chart is not necessarily non-essential. Nor is it that whatever is found outside the phonemic chart is all-essential. Just as the morphological and syntactical structures of any two languages are different in their specific ways so are the phonological structures of any two languages different in their specific ways. And the main point stressed in this short article is that a knowledge of the phonemic charts alone is not enough in the teaching of foreign languages. One must be acquainted with the phonological structures as well. 